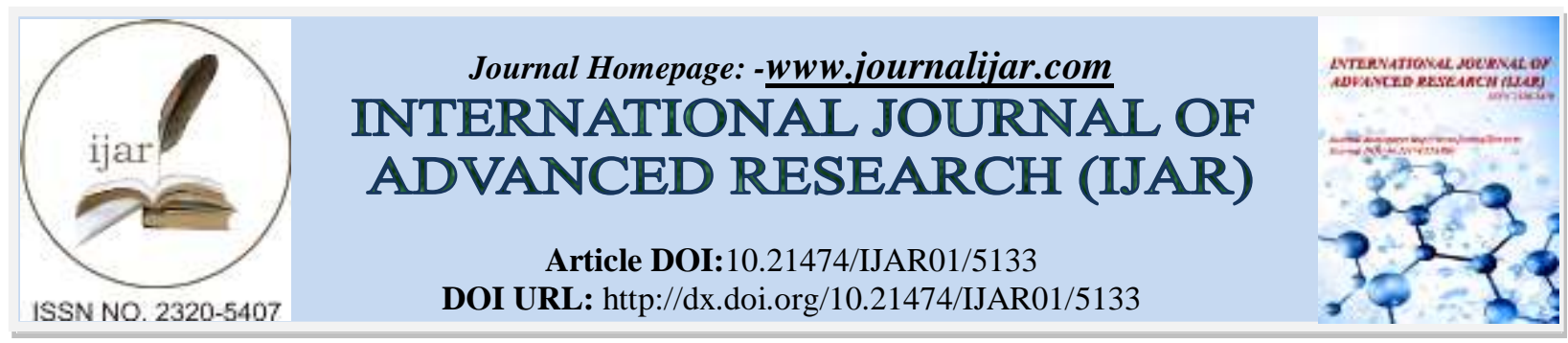

RESEARCH ARTICLE

\title{
RENAL AMYLOIDOSIS SECONDARY TO UNDIFFERENTIATED CONNECTIVE TISSUE DISORDERS: A RARE CASE REPORT FROM INDIA.
}

\author{
Dr. Hariharan Munganda, Dr.Jitendrakumar, Dr. Punitpruthi, Dr. Sandip Bhattacharya, Dr Uma rani and \\ Dr. Shilpa Gupta. \\ Asian Institute of Medical Sciences, Faridabad, Haryana, India -121001.
}

\section{Manuscript Info}

Manuscript History

Received: 10 June 2017

Final Accepted: 12 July 2017

Published: August 2017

Key words:-

Renal amyloidosis, Vasculitis, Undifferentiated connective tissue disease, Nephrotic syndrome, Massive proteinuria

\begin{abstract}
Introduction: The undifferentiated connective tissue disease (UCTD) are the type of clinical entity where the patients share the clinical symptoms of different connective tissue diseases but do not exactly fit into any particular classification criteria of a particular connective tissue disease. Amyloidosis as such secondary to vasculitis is common but those subsequent to undifferentiated vasculitis is not so common entity .Here we are presenting one such interesting case from India.

Case details: We present about a patient of 47 years non-smoker male patient who was a known case of peripheral vascular disease underwent right popliteal bypass, right 2 nd toe amputation , left below knee amputation and left brachioradial bypass due to frost bite. $\mathrm{He}$ was admitted in our hospital with complaints of multiple vomitingsand generalized weakness, fever and poor oral intake since 3-4 days.His serum ANA/ANF by EIA was moderately positive ,Lupus anticoagulant by DRVVT method is positive ,serum lupus like anticoagulant is positive ,PT 25.2 secs ,INR 2.60 APTT raised 38.3 secs, 24 hours urinary protein $16121 \mathrm{mg} / 24$ hours , Renal biopsy showed amyloidosis, Doppler scan showed common femoral artery and superficial femoral artery has biphasic flow pattern, suggestive of distal obstruction, popliteal artery and anterior tibial artery, show diminished collateralized flow pattern, no flow seen in posterior tibial artery and dorsalispedis artery.

Discussion: Renal amyloidosis can occur as secondary to Undifferentiated connective tissue disorder as one of the complication due to chronic inflammation. Early diagnosis helps in reducing mortality.
\end{abstract}

Copy Right, IJAR, 2017,. All rights reserved.

\section{Introduction:-}

The undifferentiated connective tissue disease (UCTD) are the type of clinical entity where the patients share the clinical symptoms of different connective tissue diseases but do not exactly fit into any particular classification criteria of a particular connective tissue disease.[1] .Amyloidosis have different types of clinical presentations and high level of suspicion is needed for diagnosis .Amyloidosis should be always kept in mind when multiple systems are affected and early diagnosis of such cases is important to reduce mortality rate .In our case a high range of 24 
hours urine protein gave a hint to go for renal biopsy and confirmed our diagnosis. Amyloidosis as such secondary to vasculitis is common but those subsequent to undifferentiated vasculitis is not so common entity .Here we are presenting one such interesting case from India.

\section{Case report:-}

A 47 years male Patient who was a known case of peripheral vascular disease with right popliteal bypass and right $2^{\text {nd }}$ toe amputation, left below knee amputation due to frost bite left brachioradial bypass, history of multiple vomitings and weakness, fever and poor oral intake since 3-4 days, he is a chronic smoker, non-alcoholic. BP 130/80 mmHg Pulse rate 90/min Temperature 99*F, RBS $92 \mathrm{mg} / \mathrm{dl} \quad \mathrm{SPO}_{2}-96 \%$ room air at admission GCS E4V5M6, CVS -s1s2+ Lungs -Bilateral air entry, no accessory sounds, Per abdomen-soft, Haemoglobin 12gms/dl, TLC 18.6 cells/cu.mm, Neutrophils 86\%, monocytes 7\%, lymphocytes 7\%, CRP 20.32 mg/dl, PT 25.2 secs, INR 2.60 APTT raised $38.3 \mathrm{secs}$, TIBC $100 \mathrm{microgm} / \mathrm{dl}$, S.Iron 16microgm/dl, BUN 29mg/dl, Serum creatinine $2.3 \mathrm{mg} / \mathrm{dl}$, SGOT $22 \mathrm{U} / \mathrm{L}$, SGPT $5 \mathrm{U} / \mathrm{L}$, GGT 57U/L, Blood group B positive, procalcitonin 6.01ng/ml, blood culture sterile, smear for malarial parasite is negative, Dengue serology negative, Widal test negative, urine culture sterile ,urine routine showed protein 4+ and WBC 10-15 granular waxy casts, TSH 14 mIU/l, T4 0.68 mIU/L, T3 normal , 24 hours urinary protein $16121 \mathrm{mg} / 24$ hours, total cholesterol 146mg/dl, HDL 29mg/dl, LDL 83mg/dl triglycerides $118 \mathrm{mg} / \mathrm{dl}$, Chikungunya antibodies test negative, serum vitamin D levels are low $13.3 \mathrm{ng} / \mathrm{ml}$, HIV and HBs Ag and HCV are negative, CKMB 11.9IU/L, ECG low limb lead voltage , troponin -I $669 \mathrm{ng} / \mathrm{ml}$, NT pro BNP $>25000 \mathrm{pg} / \mathrm{ml}$, Right lower limb arterial Doppler scan showed common femoral artery and superficial femoral artery has biphasic flow pattern, suggestive of distal obstruction, popliteal artery and anterior tibial artery, show diminished collateralized flow pattern, no flow seen in posterior tibial artery and dorsalispedis artery, 2D echo showed no RWMA and EF 60\%, peripheral smear showed RBC are normocytic and normochromic, platelets showed thrombosis, WBC showed neutrophilicleucocytosis, No hemoparasite seen, serum ferritin $563 \mathrm{mg} / \mathrm{dl}$, bone marrow biopsy showed reactive marrow, serum anti CCP antibodies negative, $\beta 2$ glycoprotein IgG antibodies negative, serum IgGcardiolipin antibodies negative, extractable nuclear antigen of U1RNP, Sm and SS-A are negative, Rheumatoid factor 20iu/ml was normal, serum magnesium 1.7 , ESR 115mm/hr , HbA1c $6.2 \mathrm{mmol} / \mathrm{L}$ ,RBS $112 \mathrm{mg} / \mathrm{dl}$, USG abdomen shows grade 1 fatty liver, mild right pleural effusion, mild ascites. Immunoglobulin IgG $845 \mathrm{mg} / \mathrm{dl}$, IgM 61mg/dl, IgA 285mg/dl kappa free light chains 120 lambda free light chain 90, kappa/lambda ratio is 1.330 , high resolution serum protein immunofixation electrophoresis showed no abnormal bands or $\mathrm{M}$ spike and identified polyclonal gamma globulin to consist mainly of IgG, kappa and lambda with fair amount of IgA. factor $\mathrm{V}$ leiden mutation negative, prothrombin gene mutation negative MTHFR gene mutation negative; antithrombin activity functional - normal range, pANCA and cANCA were negative., ANA/ANF by EIA was moderately positive, lupus anticoagulant by DRVVT method is positive, serum C3 and C4 levels are normal, protein $\mathrm{C}$ is normal, serum lupus like anticoagulant is positive, serum anti ds DNA antibody is negative . Renal biopsy showed amyloidosis with glomerular and vascular deposit of amyloid, patchy acute tubular injury, multifocal acute and chronic interstitial inflammation along with single foci of granuloma formation.

Patient was treated with tab Natrise 30mg BD per oral, InjColistin IV 4 million units OD ,Injmetrogyl 400mg IV BD , Inj fentanyl IV infusion as per need, Inj Noradrenaline iv infusion as per need, InjCancidas 50mg IV OD , tab Shelcal 500mg BD per oral, injTargocid, tab Atorvas, InjMeropenem iv $500 \mathrm{mg}$ BD, cap Lumia per oral 60,000 IU once weekly, tab Thyronorm $50 \mathrm{mcg}$ per oral OD, tab Practin per oral 4mg BD.

Patient was planned for right popliteal artery reconstruction due to obstruction and risk of further ischemia but patient was desaturated and GCS decreased and patient was ventilated and later expired. 


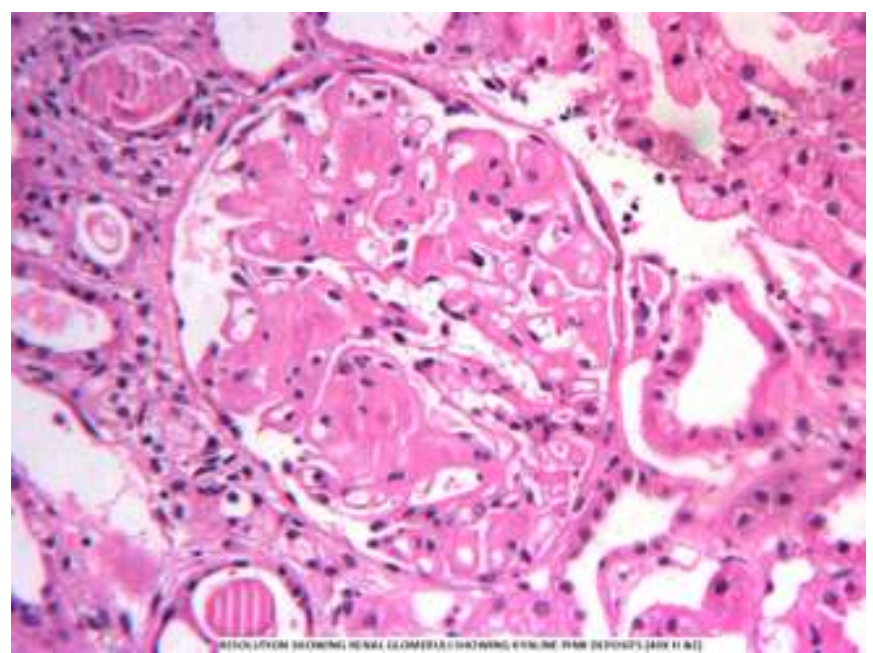

Figure 1:-H \& E stain 40x resolution showing pink hyaline renal glomeruli

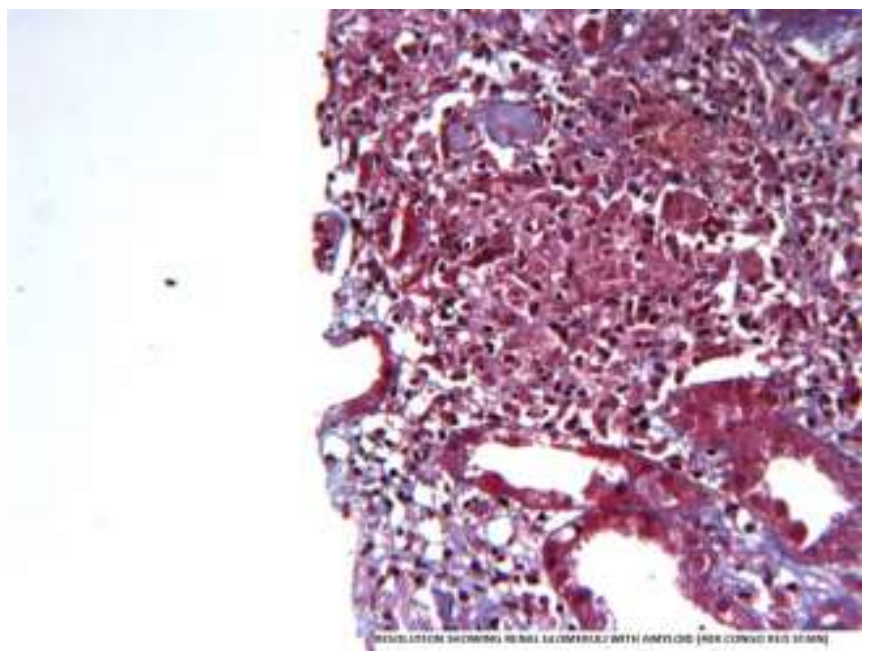

Figure 2:-Congo red showing renal glomeruli with amyloid 40x resolution

\section{Discussion:-}

The entity undifferentiated connective tissue diseases represents those systemic autoimmune disease that do not satisfy the classificative criteria for defined connective tissue diseases (CTD) such as systemic lupus erythematosus (SLE), Sjogren's syndrome (SS), rheumatoid arthritis (RA) and others. These are characterised by arthritis and arthralgias, Raynaud's phenomenon, leukopenia, while neurological and kidney involvement are virtually absent. Eighty percent of these patients have a single autoantibody specificity, more frequently anti-Ro and anti-RNP antibodies. There is no definite classification propsed to these conditions yet. [1]

The prevalence of AA amyloidosis in patients with RA has been estimated to be 5\%-78\%; whereas, it is 10\%-13\% in patients with Familial Mediterrian Fever. [1]

The distribution of amyloid light-chain (AL) amyloidosis and amyloid A (AA) amyloidosis varies, the former variety is more common in developed countries, while the latter is seen in developing countries.[1]

Almost all organs are affected including liver, spleen, heart, brain, kidney, nerves, skin and soft tissues.

Some patients who have an undifferentiated diagnosis at onset, may develop a well-defined particular CTD subsequently. This process is generally completed after 5 to 10 years of the disease onset. Persistent chronic inflammatory disease is the most common cause of secondary renal amyloidosis or AA amyloidosis. [2] 
In renal amyloidosis, amyloid deposits shows different distribution patterns most commonly involving glomerular compartment, approximately in most of the cases. The vascular pattern of renal amyloidosis may be found in few cases. [2]

Massive Proteinuria leading to nephrotic syndrome and renal failure is the prominent clinical feature that should raise suspicion of AA amyloidosis in patients with chronic inflammatory conditions. Proteinuria is seen in most of the patients that determines prognosis. Although amyloid deposits are common in the liver and spleen, their clinical significance is relatively minor in the early stages of the disease. [3][4]

Diagnosis of amyloidosis is mostly based on organ involvement and histopathology of amyloid deposits. For amyloid deposits Congo red and metachromatic birefringence under unidirectional polarized light remain the gold standard. The biopsy sites such as abdominal fat (most preferred site), rectal mucosa, or minor salivary glands are preferred.[5]

Congo red is still considered the gold standard for differentiating amyloid from other protein deposits with the classic apple-green birefringence under polarized light .[6]

The 123I-labeled serum amyloid $\mathrm{P}$ component scintigraphy is useful in defining the subtype pattern of amyloid.[7] New techniques, such as the proteomic analysis by mass spectrometry, are emerging as powerful complementary tools to improve amyloid typing.[8]

Another likely diagnostic possibility of massive proteinuria would include nephrotic syndrome contributing to proteinuric illness, associated with NSAIDS.[9]

Because of varied etiologic diversity of AA amyloidosis, the available treatment options are few.[10]

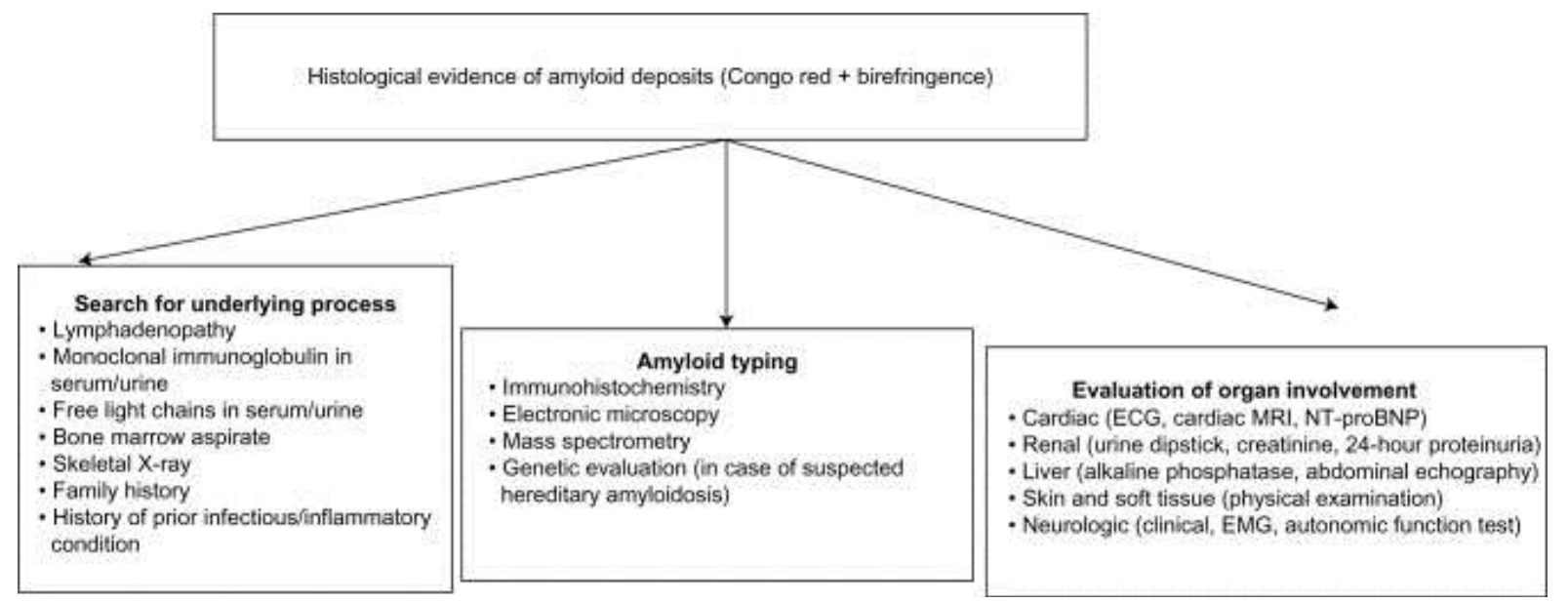

Figure 3:-Diagnostic algorithm in patients with suspected amyloidosis.[11]

Table 1:-Criteria for organ involvement in AL amyloidosis [11]

\begin{tabular}{|l|l|l|}
\hline Organ & Test & Criteria \\
\hline Kidney & 24-hour urine & Proteinuria $\geq 0.5 \mathrm{~g} / 24 \mathrm{~h}$, predominantly albumin \\
\hline \multirow{5}{*}{ Heart } & ECG & Voltage $<5 \mathrm{~mm}$ in all limb leads (indirect criterion) \\
\cline { 2 - 3 } & NT-proBNP & Normal values practically exclude myocardial involvement \\
\cline { 2 - 3 } & Echocardiogram & Mean wall thickness $>12 \mathrm{~mm}$; no other cardiac cause \\
\cline { 2 - 3 } & $\begin{array}{l}\text { Combination of ECG ventricular hypertrophy and low voltage on ECG } \\
\text { strongly suggests myocardial involvement }\end{array}$ \\
\cline { 2 - 3 } & Cardiac MRI & Delay in subendocardial gadolinium enhancement \\
\hline \multirow{2}{*}{ Liver } & $\begin{array}{l}\text { Alkaline } \\
\text { phosphatase }\end{array}$ & Value $>1.5 \times$ upper limit of normal \\
\cline { 2 - 3 } & Imaging studies & Hepatomegaly $>15 \mathrm{~cm}$ in the absence of heart failure \\
\hline
\end{tabular}




\begin{tabular}{|c|c|c|}
\hline $\begin{array}{l}\text { Gastrointestinal } \\
\text { tract }\end{array}$ & Direct biopsy & Histological \\
\hline \multirow[t]{4}{*}{ Nerve } & Clinical & \multirow[t]{2}{*}{ Symmetric lower extremity sensorimotor peripheral neuropathy } \\
\hline & EMG & \\
\hline & \multirow{2}{*}{$\begin{array}{l}\text { Autonomic function } \\
\text { tests }\end{array}$} & Severe orthostatic hypotension \\
\hline & & $\begin{array}{l}\text { Intestinal dysmotility (gastric emptying disorder, pseudo-obstruction, } \\
\text { voiding dysfunction) }\end{array}$ \\
\hline \multirow[t]{2}{*}{ Lung } & Imaging studies & Diffuse bilateral interstitial pattern \\
\hline & Direct biopsy & Histological \\
\hline \multirow{3}{*}{$\begin{array}{l}\text { Skin and soft } \\
\text { tissue }\end{array}$} & Clinical & Macroglossia, jaw claudication, skin lesions \\
\hline & EMG & Carpal tunnel syndrome \\
\hline & Direct biopsy & Histological \\
\hline
\end{tabular}

Note: Only criteria marked in bold are considered major criteria for the diagnosis of organ involvement in AL amyloidosis.

\section{Useful treatments for systemic AA amyloidosis:[11]}

Treatments targeting underlying predisposing disease, Neoplasm: chemotherapy, surgery, Infectious diseases: antibiotic therapy, Autoimmune diseases: methotrexate; leflunomide; chlorambucil; tacrolimus; infliximab; etanercept; abatacept; colchicine; anakinra; canakinumab, Treatments targeting amyloidosis: tocilizumab; dimethylsulfoxide; eprodisate; heparins; statins, Supportive treatment: Orthostatic hypotension: fludrocortisone; midodrine, Malabsorptive syndromes and gastrointestinal dysautonomia: antibiotic therapy; corticosteroid pulses; and combination treatment with octreotide Novel therapeutic options: anti-SAP antibodies (CPHPC); antisense complementary oligonucleotides; and phagocytic depletion with clodronate. Undifferentiated connective tissue disorder with secondary amyloidosis is one of the complication due to chronic inflammation. Amyloidosis Secondary to vasculitis should be kept in differential diagnosis in such cases. 24 hours urine protein may guide in diagnosis and the need for renal biopsy when diagnostic ambivalence arises due to equivocal vasculitic profile laboratory tests.[11]

\section{Conclusion:-}

Undifferentiated connective tissue disease may lead to renal involvement in the form of renal amyloidosis. Early diagnosis helps in reducing mortality. Amyloidosis should be suspected in these type of cases .Renal biopsy is indicated in mixed connective tissue disorder for early diagnosis of secondary amyloidosis.

\section{References:-}

1. Mosca M1, Neri R, BombardieriS.,Undifferentiated connective tissue diseases (UCTD): a review of the literature and a proposal for preliminary classification criteria.,ClinExpRheumatol. 1999 Sep-Oct;17(5):615-20.

2. Sham Sunder, SatyanandSathi, HimanshuMahapatra, Rajesh J,Anurag Gupta, Prabhu K Undifferentiated connective tissue disease presenting with vascular pattern of renal amyloidosis with carpel tunnel syndrome: A case report ;IJCRI - International Journal of Case Reports and Images, Vol. 5 No. 6, June 2014. ISSN - [09763198]

3. Bulum T1, Prkacin I, Cavrić G, Sobocan N, Skurla B, Duvnjak L, Bulimbasić S. [Secondary (AA) amyloidosis in Crohn's disease].Acta Med Croatica. 2011;65(3):271-8.

4. Ellie Kelepouris, MD, FAHA,Zalman S Agus, MD,Richard J Glassock, MD, MACP ,Alice M Sheridan, MDOverview of heavy proteinuria and the nephrotic syndrome , http://cursoenarm.net/UPTODATE/contents/mobipreview.htm?26/11/26800?source=see_link

5. *Stefan O. Scho“nland,1 *Ute Hegenbart,1 Tilmann Bochtler,1 Anja Mangatter,1 Marion Hansberg,1 Anthony D. Ho, 1 Peter Lohse, 2 and Christoph Ro“cken3Immunohistochemistry in the classification of systemic forms of amyloidosis: a systematic investigation of 117 patients ,Bloodjournal.org, American Society of hematology.

6. M. H. van Rijswijk, MD, and C. W. G. J. van Heusden, MDThe Potassium Permanganate Method,A Reliable Methodfor Differentiating Amyloid AA From ,Other Forms ofAmyloid in RoutineLaboratoryPractice,https://www.ncbi.nlm.nih.gov/pmc/articles/PMC2042379/pdf/amjpathol002360051.pdf.

7. Hazenberg BP1, van Rijswijk MH, Piers DA, Lub-de Hooge MN, Vellenga E, Haagsma EB, Hawkins PN, Jager PL. Diagnostic performance of 123I-labeled serum amyloid P component scintigraphy in patients with amyloidosis.Am J Med. 2006 Apr;119(4):355.e15-24. 
8. Sarah J Parker,2,3,* Koen Raedschelders,3,* and Jennifer E Van Eyk1,3 Emerging proteomic technologies for elucidating context-dependent cellular signaling events: A big challenge of tiny proportions Proteomics. 2015 May; 15(9): 1486-1502.

9. MICHAEL F. CARROLL, M.D., and JONATHAN L. TEMTE, M.D., PH.D., University of WisconsinMadison Medical School, Madison, Wisconsin ,Proteinuria in Adults: A Diagnostic Approach Am Fam Physician. 2000 Sep 15;62(6):1333-1340.

10. Susan C. Shin, MD and Jessica Robinson-Papp, MD, MSMt Sinai J Med, AMYLOID NEUROPATHIES ,Mt Sinai J Med. 2012 Nov; 79(6): 733-748.

11. Diego Real de Asúa, Ramón Costa, Jose MaríaGalván, María Teresa Filigheddu, Davinia Trujillo, and JulenCadiñanos ,Systemic AA amyloidosis: epidemiology, diagnosis, and management, ClinEpidemiol. 2014; 6: 369-377.Published online 2014 Oct 29. doi: 10.2147/CLEP.S39981 PMCID: PMC4218891. 